\title{
Questes
}

vestes Revue pluridisciplinaire d'études médiévales

11 | 2007

La transmission

\section{La transmission : avant-propos}

Michel Sot

\section{(2) OpenEdition}

Journals

Édition électronique

URL : http://journals.openedition.org/questes/540

DOI : 10.4000/questes.540

ISSN : 2109-9472

\section{Éditeur}

Les Amis de Questes

\section{Édition imprimée}

Date de publication : 15 mars 2007

Pagination : 1-2

ISSN : 2102-7188

\section{Référence électronique}

Michel Sot, "La transmission : avant-propos », Questes [En ligne], 11 | 2007, mis en ligne le 01 janvier 2014, consulté le 22 septembre 2020. URL : http://journals.openedition.org/questes/540 ; DOI : https://doi.org/10.4000/questes.540 


\section{Transmettre.}

L'homme ou la femme n'ont qu'une chose à transmettre : leur propre être, c'est-à-dire la vie. Transmettre la vie, au sens biologique, bien sûr, mais nous sommes déjà là au cour des relations entre hommes et femmes, de leurs interrogations sur l'amour et la mort, qui sont de grands objets d'investigation de la littérature comme de l'histoire. Toutes les autres transmissions sont peu ou prou des produits de cette transmission primordiale.

On s'est, au long des temps, préoccupé de la transmission des biens et il n'est pas nécessaire de chercher bien loin pour trouver des «problèmes de successions » dans les familles. En transmettant un patrimoine, immobilier et mobilier, on transmet des richesses matérielles sans doute, mais bien autre chose aussi : les biens d'un père et d'une mère n'ont pas seulement une valeur marchande, justement parce qu'ils sont transmis par eux.

Avec la vie, ils ont transmis des biens qui sont autant de signes de ce qu'ils ont transmis d'autre : des valeurs, des savoirs, tout ce qui permet d'être, et que l'on appelle parfois «patrimoine immatériel». Et de ce dernier, qui n'est pas quantifiable, personne n'est sûr d'en avoir reçu la part qu'il estime juste.

Pour toutes ces transmissions, des spécialistes sont apparus au cours de l'histoire. La transmission de la vie biologique a fait appel aux guérisseurs, magiciens et médecins, ces derniers, avec les biologistes, prenant une importance croissante et peut-être excessive dans les décennies récentes. La transmission des richesses implique l'intervention de spécialistes du droit, les notaires, mais aussi d'experts capables d'estimation des valeurs marchandes. Et la transmission du patrimoine immatériel ? Ici interviennent les hommes et les femmes de savoir, le clergé au Moyen Âge, tous les enseignants, formateurs et autres animateurs aujourd'hui.

Les études ici présentées s'interrogent sur l'acte de transmettre au Moyen Âge. Elles s'inscrivent dans la création médiévale, ancrée dans ses racines romaines, transmises avec plus ou moins de fidélité et réinventées à la fois dans un Éloge de Florence au $\mathrm{XV}^{\mathrm{e}}$ siècle, ou dans ses racines bretonnes, elles aussi au moins autant crées que transmises, autour du roi Arthur: Excalibur est autre 
chose qu'une épée, comme l'arme de Guiron dans le roman du même nom. Ces études nous montrent comment la transmission est une appropriation par le récepteur, qui profite de l'héritage, mais qui le modifie. Il peut même l'inventer, ou au moins l'emprunter : la famille des Trincy, seigneurs de Foligno aux XIII ${ }^{\mathrm{e}}$ et $\mathrm{XIV}^{\mathrm{e}}$ siècles, découvre ses origines troyennes, via Romulus et Remus. Les structures de parenté, mises en valeur par l'anthropologie du dernier demi-siècle, informent l'articulation de divers modes de transmission dans le roman Ille et Galeron de Gautier d'Arras, où il apparaît nettement que la parenté biologique s'efface derrière des liens de parenté artificiels de diverse nature. Transmission d'anecdotes édifiantes du père au fils dans le Chastoiement d'un père à son fils (début XIII ${ }^{\mathrm{e}}$ s.), transmission ou retransmission de la Queste du Saint Graal par le Tristan en prose, ou transmission du savoir magique de Merlin, la fécondité du thème de recherche manifeste bien sa place centrale dans une réflexion sur la culture médiévale.

L'historien qui a accepté d'écrire ces lignes d'introduction sent derrière chacune des transmissions étudiées, de leurs modalités et de leurs résultats, le modèle de la transmission médiévale par excellence : celle de la parole de Dieu. Les hommes du Moyen Âge ont transmis les livres de la Bible qu'ils n'ont cessé de réinterpréter : c'est l'exégèse. Ils ont transmis des pratiques religieuses, qu'ils n'ont cessé de réinventer : c'est la liturgie. Ainsi l'homme s'inscrit-il dans un continuum de l'histoire, du commencement à la fin, de la Genèse à l'Apocalypse.

Transmettre, c'est aussi créer. 